\title{
Pemberdayaan Kader Pos Kesehatan Pesantren (POSKESTREN) dalam Penanganan Kegawatdaruratan di Pondok Pesantren Jabal Nur Kandis Kabupaten Siak Riau
}

\author{
Fajri Marindra Siregar, Riki Sukiandra \\ Fakultas Kedokteran, Universitas Riau \\ E-mail: fajrifkunri@gmail.com
}

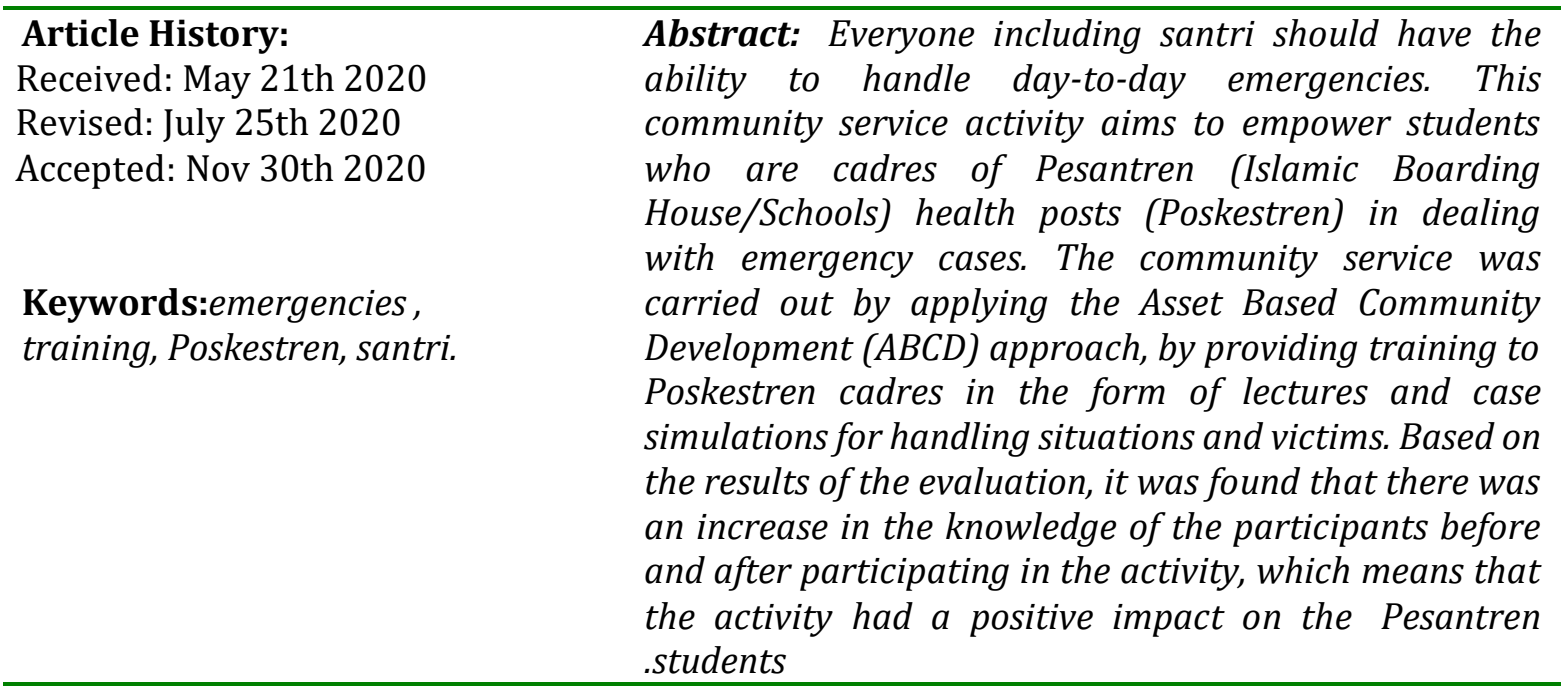

\section{Pendahuluan}

Keadaan darurat dapat terjadi kapanpun, dimanapun, dan pada siapapun tanpa terkecuali. ${ }^{1}$ Berdasarkan data Riskesdas tahun 2018 ,di Indonesia pr oporsi cedera yang mengakibatkan kegiatan sehari- hari terganggu masih cukup tinggi yaitu9,2\%, dimana sebanyak12,2 \%nya terjadi pada usia remaja 15-24tahun dan sebesar 6,5\% terjadi di sekolah dan lingkungannya. ${ }^{2}$ Pada dasarnya keadaan gawat maupun darurat tersebut perlu dipersiapkan tentang bagaimana cara mengatasinya, agar tidak menimbulkan kerugian yang besar, atau setidaknya dapat meminimalisir kerugian yang muncul. ${ }^{3}$ Kegiatan pelatihan penanganan kegawatdaruratan sehari- hari ini bertujuan untuk .melatih peserta secara aktif melakukan pertolongan pertama pada kegawatdaruratan

Kemampuan dalam pelayanan kesehatan kegawatdaruratan sehari-hari merupakan kewajiban yang harus dimiliki oleh setiap orang, bukan hanya tenaga

\footnotetext{
${ }^{1}$ Lindung Siswanto, "Sistem Informasi Manajemen Komando Tanggap Darurat Bencana Letusan Gunung Merapi,” Jurnal Teknologi Informasi 7, no. 19 (2012): 15-24.

2 R I Riskesdas, “Laporan Nasional Riskesdas Tahun 2018” (Jakarta, 2018).

${ }^{3}$ Erna Suryani, Wahyu Naris Wari, and Siska Aprilia Hardiyanti, "Edukasi Dan Pelatihan Simulasi Tanggap Darurat Bencana Kebakaran Bagi Santri Di Banyuwagi," JMM (Jurnal Masyarakat Mandiri) (2019): 132-138; Toha Masum and Muh Barid Nizarudin Wajdi, "Pengembangan Kemandirian Pesantren Melalui Program Santripreneur," Engagement: Jurnal Pengabdian Kepada Masyarakat 2, no. 2 (2018): 221-232.
} 
kesehatan. Masyarakat awam termasuk para santri diharapkan juga mampu untuk dapat melakukan pelayanan kesehatan kegawatdaruratan di lingkungannya. Kegawatdaruratan yang membutuhkan penanganan segera misalnya, pingsan, patah tulang, tersedak, tersengat listrik, cedera, keracunan dan lainnya. Kunci keberhasilan penanganan kegawatdaruratan tergantung pada kecepatan dan ketepatan penolong dalam memberikan pertolongan. Korban diharapkan sudah mendapatkan pertolongan pertama minimal10 menit setelah kegawatdaruratan terjadi. ${ }^{4}$

Kegiatan pengabdian ini dilaksanakan pada Pondok Pesantren Jabal Nur Kandis, Kabupaten Siak, Riau. Mitra ini dipilih karena merupakan salah satu ponpes terbesar di provinsi Riau. Hingga saat ini santri Pondok Pesantren Jabal Nur Kandis telah mencapai 900orang Pondok Pesantren Jabal Nur Kandis terletak cukup jauh dari fasilitas . kesehatan. Berdasarkan wawancara dengan pihak pesantren, walaupun Pondok Pesantren Pondok Pesantren Jabal Nur Kandis telah memiliki perangkat Pondok Kesehatan Pesantren(POSKESTREN) ,namun para santri belum pernah mendapatkan pelatihan dari tenaga kesehatan ,khususnya mengenai keterampilan penanganan kegawatdaruratan .Oleh karena itu ,kegiatan pengabdian ini bertujuan untuk memberdayakan para santri yang merupakan kader POSKESTREN dalam menghadapi kasus kegawatdaruratan.

\section{Metode}

Kegiatan pengabdian masyarakat ini dilaksanakan di Pondok Pesantren Jabal Nur Kandis, yang beralamat di Jl. Sultan Syarif Hasyim, Simpang Belutu, Kandis, Kabupaten Siak, Riau28686. Adapun pendekatan yang digunakan adalah Asset Based Community . Development $(A B C D)$.Pendekatan ini menekankan pada inventarisasi asset yang terdapat di dalam masyarakat yang dipandang mendukung pada kegiatan pemberdayaan masyarakat.

Pelaksanaan kegiatan pengabdian dilakukan pada bulan Oktober 2020. Kegiatan diawali dengan survey pendahuluan ke lokasi pengabdian. Tahapan ini bertujuan untuk mengurus perizinan dan penilaian awal terhadap mitra. Berdasarkan hasil wawancara didapatkan mitra telah memiliki aset berupa POSKESTREN dan kader dengan motivasi belajar yang kuat. Walau demikian, keterampilan yang dimiliki oleh kader masih terbatas karena belum adanya pelatihan khusus dari pihak puskesmas setempat.

Berdasarkan hal tersebut, bersama mitra disepakati untuk dilaksanakan pemberdayaan kader POSKESTREN berupa pelatihan penanganan kegawatdaruratan. Karena merujuk Buku Pedoman Penyelenggaraan Pos Kesehatan Pesantren oleh Kemenkes RI, keterampilan kegawatdaruratan merupakan salah satu keterampilan yang

${ }^{4}$ Arif Mahrur, "Faktor-Faktor Yang Mempengaruhi Lamanya Waktu Tanggap Dalam Pelayanan Gawat Darurat Di Instalasi Gawat Darurat RSUD Dr. Soedirman Kebumen" (STIKES Muhammadiyah Gombong, 2015). 
perlu dimiliki oleh kader dan beberapa kali pesantren memiliki pengalaman terkait masalah ini seperti kasus kecelakaan. Adapun yang menjadi sasaran pemberdayaan adalah santri yang merupakan kader POSKESTREN Jabal Nur Kandis, yang terdiri dari15 santri dan15 santriwati dengan rentang usia15-17 tahun.

Pemberdayaan aset diberikan dalam bentuk pelatihan yang diperlihatkan oleh gambar 1. Para kader POSKESTREN diberikan edukasi mengenai kegawatdaruratan dan bagaimana penanganan yang dapat dilakukan oleh orang awam dalam bentuk ceramah. Untuk mengasah keterampilan peserta, kegiatan pelatihan ini juga disampaikan dalam bentuk simulasi kasus, sehingga para peserta juga belajar mengaplikasikan teori-teori yang didapat. Para peserta juga diberikan buku saku yang berisikan materi mengenai penanganan kegawatdaruratan sehari-hari. Lalu diakhir sesi, kegiatan dilanjutkan dengan proses tanya jawab atau diskusi sehingga para peserta diberi kesempatan untuk menyampaikan hal-hal yang belum mereka mengerti. Berhubung dengan adalah pandemi COVID-19 seluruh kegiatan dilaksanakan dengan menerapkan protokol kesehatan secara ketat.

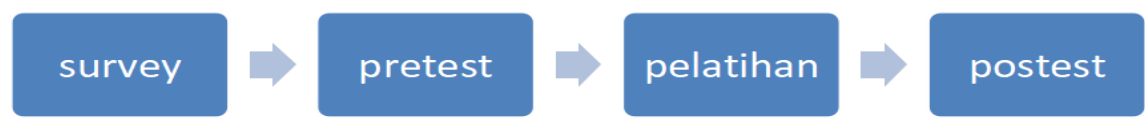

Gambar1Metode pelaksanaan kegiatan .

Adapun untuk evaluasi, kepada para peserta disebarkan kuisioner pretest dan postest untuk melihat perubahan tingkat pengetahuan peserta. Hasil pretest dan posttest dipaparkan secara univariat menggunakan statistik deskriptif, kemudian dibandingkan -dengan uji statistik menggunakan uji nonparametrik W.ilcoxon

\section{Hasil}

Kegiatan pemberdayaan kader POSKESTREN dalam penanganan kegawatdaruratan di Pondok Pesantren Jabal Nur Kandis, Siak terlaksana pada bulan Oktober2020 Kader POSKESTREN yang menjadi sasaran pengabdian masyarakat ini . merupakan aset Pondok Pesantren Jabal Nur Kandis khususnya dalam menjaga kesehatan di lingkungan Pesantren, sehingga menjadi fokus pemberdayaan pada kegiatan pengabdian kepada masyarakat ini.

Selanjutnya kegiatan dilanjutkan dengan edukasi kepada para kader dengan menyampaikan materi mengenai bantuan hidup dasar(BHD) oleh narasumber dr. Riki Sukiandra, SpS dan simulasi kasus oleh dr. Fajri Marindra, M. Biomed( Gambar3 .(Para peserta juga diberikan kesempatan untuk bertanya mengenai hal-hal yang belum dipahami .Para peserta juga diberikan buku saku yang berisikan materi mengenai 
penanganan kegawatdaruratan sehari-hari.

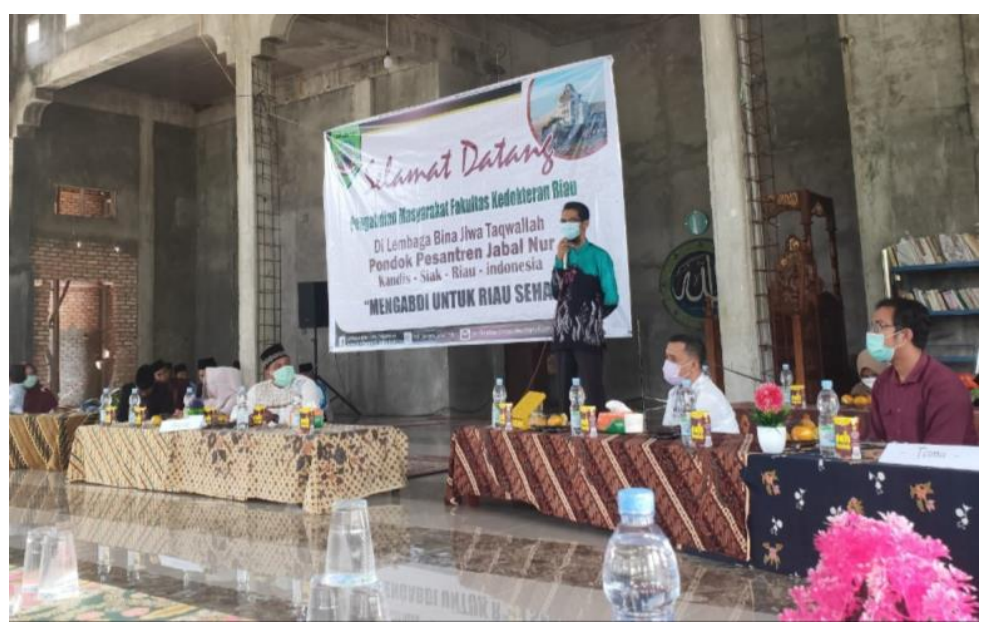

Gambar 2. Kegiatan pembukaan dan brainstorming mengenai kesehatan pesantren

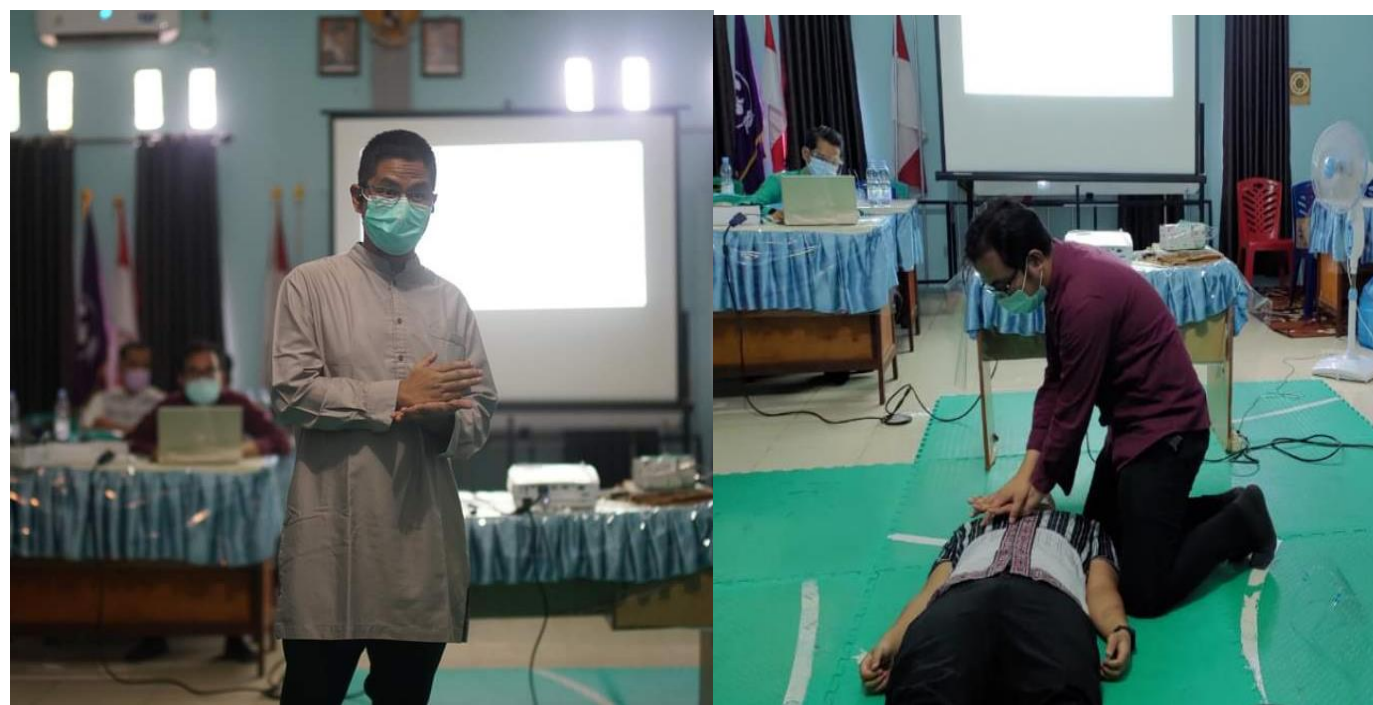

(A)

(B)

Gambar 2. Pelaksanaan pelatihan, )APemberian materi oleh dr (. Riki Sukiandra SpS. )BSimulasi kasus oleh dr (. Fajri Marindra, M.Biomed

Para peserta yang merupakan kader POSKESTREN ditekankan untuk mengingat langkah- langkah penanganan kegawatdaruratan(DRSABC) khususnya pada kasus henti nafas maupun jantung seperti yang tercantum pada Tabel1. 
Tabel1Daftar tilik kemampuan penangan kegawatdaruratan .

\begin{tabular}{ll}
\hline No & \multicolumn{1}{c}{ Item } \\
\hline 1 & Dangers(Cek bahaya) \\
\hline 2 & Response(Cek kesadaran) \\
\hline 3 & Send for help(Minta bantuan) \\
\hline 4 & Airways(Cek jalan nafas) \\
\hline 5 & Breathing(Cek pernafasan) \\
\hline 6 & Circulation( Cek sirkulasi\& mulai RJP) \\
\hline
\end{tabular}

Berdasarkan evaluasi yang dilakukan(Gambar 4), didapatkan pengetahuan peserta sebelum pelatihan memiliki nilai rerata 7 , dengan nilai terendah 55,0 dan tertinggi9,0 .Sedangkan setelah diberikan pelatihan didapatkan nilai rerata meningkat menjadi 9, 3dengan nilai terendah 6, 0dan tertinggi 10,0. Berdasarkan uji statistik didapatkan $\mathrm{p}<0$, 001yang berarti terdapat perbedaan ya ng signifikan antara pengetahuan santri sebelum dan setelah pelatihan. Perubahan ini berdampak positif (peningkatan pengetahuan) ,yang berarti kegiatan pelatihan penanganan kegawatdaruratan pada santri Pondok Pesantren bermanfaat bagi para peserta.

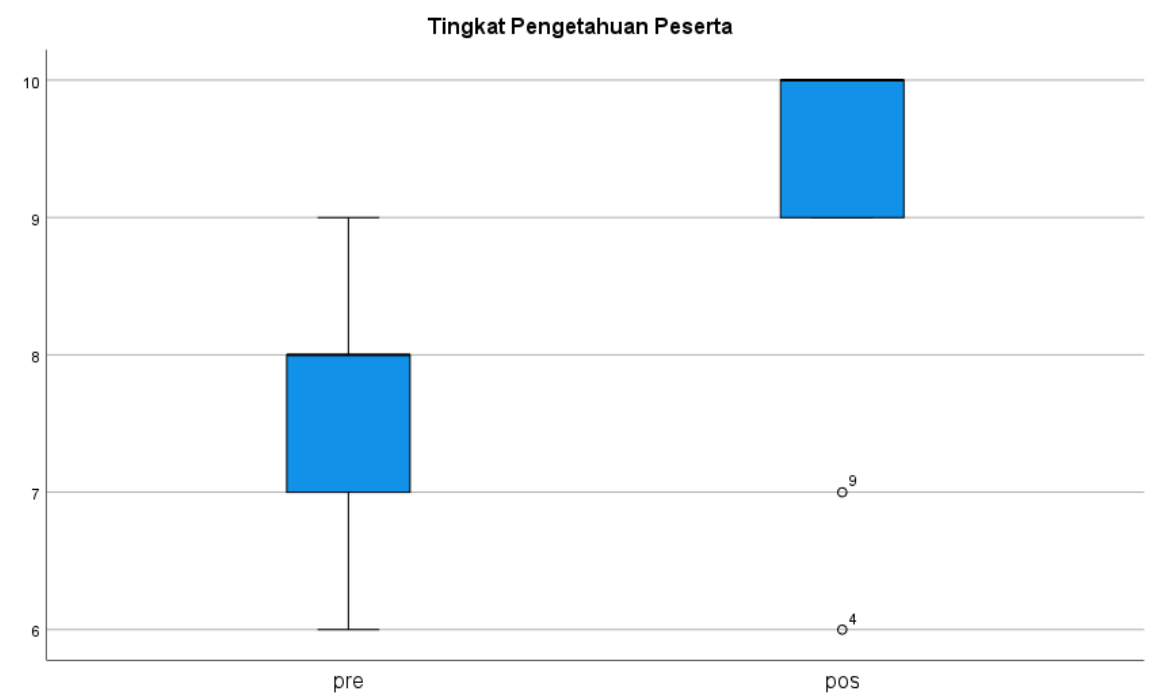

Gambar 4. Perbandingan pengetahuan kader POSKESTREN sebelum dan setelah pelatihan, $p=0,000$ (uji wilcoxon)

\section{Diskusi}


Kemampuan dalam penanganan kegawatdaruratan merupakan kewajiban yang harus dimiliki oleh setiap orang, bukan hanya tenaga kesehatan. Adanya bekal mengenai bagaimana cara mengatasi kegawatdaruratan tersebut, akan mengurangi kerugian yang besar, atau setidaknya dapat meminimalisir kerugian yang muncul. Santri sebagai kader POSKESTREN merupakan pilar terdepan dalam penanganan masalah kesehatan yang ${ }^{5}$ muncul di lingkungan pondok pesantren. Sehingga diharapkan melalui kegiatan pelatihan penanganan kegawatdaruratan ini para santri dapat secara aktif melakukan pertolongan pertama pada kasus kegawatdaruratan, seperti yang telah dilakukan oleh beberapa tim terdahulu. ${ }^{68,7}$,

Para santri yang merupakan kader dari POSKESTREN Jabal Nur Kandis, selain memiliki motivasi yang kuat juga memiliki pengalaman terlibat pada pengelolaan pondok kesehatan pesantren sehingga sangat tepat untuk diberi pelatihan kesehatan khususnya mengenai penanganan kegawatdaruratan. Materi yang diberikan pada pelatihan ini berupa bantuan hidup dasar, yang merupakan pengetahuan umum yang perlu diketahui oleh semua orang, tidak terbatas pada tenaga kesehatan. Adanya peningkatan pengetahuan berdasarkan hasil evaluasi mengindikasikan pelatihan ini memberikan dampak yang baik bagi peserta. Untuk meningkatkan pemahaman dan mengasah keterampilan peserta, diperlukan pelatihan sejenis yang dilaksanakan secara berkala( minimal2 kali setahun) dan berkelanjutan. Para kader juga diharapakan dapat berbagi ilmu dengan rekan-rekan santri lainnya, maupun santri baru agar terjadi proses kaderisasi. Dampak perubahan sosial dari kegiatan pemberdayaan ini belum dapat dinilai secara langsung, namun diharapkan kedepan jika para santri menemukan masalah kesehatan khususnya mengenai kegawatdaruratan, para santri telah memiliki pengetahuan untuk membantu penanganan kasus kegawatdaruratan tersebut.

\section{Kesimpulan}

5 M Burhanuddin Ubaidillah and Yaziidul Khooiri, "Pembentukan Medical Team Melalui Person Centered Therapy Dalam Pencegahan COVID-19 Fase Era New Normal Di Pondok Pesantren Miftahul Mubtadiin Ar-Ridlo Krempyang Tanjunganom Nganjuk," Janaka, Jurnal Pengabdian Masyarakat 3, no. 1 (2020): 16-27.

${ }^{6}$ M. Daimul Abror et al., "Pendampingan Integrated Policy and Managemen System Tata Kelola Sampah Di Pesantren Ngalah Sengonagung Purwosari Pasuruan," Engagement : Jurnal Pengabdian Kepada Masyarakat 3, no. 2 (2019): 230-244; Suryani, Wari, and Hardiyanti, "Edukasi Dan Pelatihan Simulasi Tanggap Darurat Bencana Kebakaran Bagi Santri Di Banyuwagi."

7 Dwi Nur Aini, Menik Kustriyani, and Arifianto, "PKM Pelatihan Pertolongan Pertama Dalam Gawat Darurat Pada Orang Awam," Jurnal Implementasi Pengabdian Masyarakat Kesehatan 1, no. 2 (2019): 3438; Nihayatu Aslamatis Solekah and Ulfi Kartika Oktaviana, "Penguatan Pengelolaan Ternak Wakaf Hibah Produktif Melalui Fermentasi Pakan Ternak Sebagai Alternatif Pemberdayaan Santri Menuju Pesantren Yatim Yang Mandiri," Engagement: Jurnal Pengabdian Kepada Masyarakat 1, no. 2 (2017): 170-184.

8 Sri Chanif., Maryam., Widodo, "Optimalisasi UKS Dalam Penanganan Kegawatdaruratan Di Sekolah Melalui Pelatihan Kegawatdaruratan Dasar," in The 2nd University Research Coloqium 2015, 2015, 71-79. 
Kegiatan pengabdian kepada masyarakat berupa pemberdayaan kader POSKESTREN dalam penanganan kegawatdaruratan memiliki dampak positif dalam meningkatkan pengetahuan santri akan penanganan kasus kegawatdaruratan. Pelatihan sejenis diperlukan untuk dilaksanakan secara berkala dan berkelanjutan.

\section{Pengakuan}

Penulis mengucapkan terima kasih kepada Fakultas Kedokteran Universitas Riau yang telah mendukung kegiatan ini dan kepada Pondok Pesantren Jabal Nur Kandis yang telah mengizinkan kegiatan ini sehingga dapat terlaksana.

\section{Daftar Referensi}

Abror, M. Daimul, Amang Fathurrohman, Zainul Ahwan, and Lukman Hakim. "Pendampingan Integrated Policy and Managemen System Tata Kelola Sampah Di Pesantren Ngalah Sengonagung Purwosari Pasuruan.” Engagement: Jurnal Pengabdian Kepada Masyarakat 3, no. 2 (2019): 230-244.

Aini, Dwi Nur, Menik Kustriyani, and Arifianto. "PKM Pelatihan Pertolongan Pertama Dalam Gawat Darurat Pada Orang Awam." Jurnal Implementasi Pengabdian Masyarakat Kesehatan 1, no. 2 (2019): 34-38.

Chanif., Maryam., Widodo, Sri. "Optimalisasi UKS Dalam Penanganan Kegawatdaruratan Di Sekolah Melalui Pelatihan Kegawatdaruratan Dasar." In The 2nd University Research Coloqium 2015, 71-79, 2015.

Mahrur, Arif. "Faktor-Faktor Yang Mempengaruhi Lamanya Waktu Tanggap Dalam Pelayanan Gawat Darurat Di Instalasi Gawat Darurat RSUD Dr. Soedirman Kebumen." STIKES Muhammadiyah Gombong, 2015.

Masum, Toha, and Muh Barid Nizarudin Wajdi. "Pengembangan Kemandirian Pesantren Melalui Program Santripreneur." Engagement: Jurnal Pengabdian Kepada Masyarakat 2, no. 2 (2018): 221-232.

Riskesdas, R I. “Laporan Nasional Riskesdas Tahun 2018.” Jakarta, 2018.

Siswanto, Lindung. "Sistem Informasi Manajemen Komando Tanggap Darurat Bencana Letusan Gunung Merapi.” Jurnal Teknologi Informasi 7, no. 19 (2012): 15-24.

Solekah, Nihayatu Aslamatis, and Ulfi Kartika Oktaviana. "Penguatan Pengelolaan Ternak Wakaf Hibah Produktif Melalui Fermentasi Pakan Ternak Sebagai Alternatif Pemberdayaan Santri Menuju Pesantren Yatim Yang Mandiri." Engagement: Jurnal Pengabdian Kepada Masyarakat 1, no. 2 (2017): 170-184.

Suryani, Erna, Wahyu Naris Wari, and Siska Aprilia Hardiyanti. "Edukasi Dan Pelatihan Simulasi Tanggap Darurat Bencana Kebakaran Bagi Santri Di Banyuwagi." JMM 
(Jurnal Masyarakat Mandiri) (2019): 132-138.

Ubaidillah, M Burhanuddin, and Yaziidul Khooiri. "Pembentukan Medical Team Melalui Person Centered Therapy Dalam Pencegahan COVID-19 Fase Era New Normal Di Pondok Pesantren Miftahul Mubtadiin Ar-Ridlo Krempyang Tanjunganom Nganjuk." Janaka, Jurnal Pengabdian Masyarakat 3, no. 1 (2020): 16-27. 